\title{
Microbial communities analysis assessed by pyrosequencing-a new approach applied to conservation state studies of mural paintings
}

\author{
T. Rosado • J. Mirão • A. Candeias • A. T. Caldeira
}

Received: 18 August 2013 /Revised: 28 October 2013 / Accepted: 16 November 2013 / Published online: 12 December 2013

(C) Springer-Verlag Berlin Heidelberg 2013

\begin{abstract}
The knowledge about the microbial communities present in mural paintings is of utmost importance to develop effective conservation and mitigation strategies. The present paper describes a methodological approach for the detailed characterisation of microorganisms thriving in mural paintings by combining culture-dependent methods that allow the identification of microorganisms capable of growing in the laboratory conditions and to obtain high cell densities for further studies, and culture independent methods, such as denaturing gradient gel electrophoresis (DGGE) and pyrosequencing. The coupled use of culture-dependent methods and DGGE does not give enough information to investigate the diversity and abundance of microorganisms present in wall paintings. Pyrosequencing, a novel molecular technique, used here for the first time in this area of research, allowed the identification of a large number of microorganisms, confirming some already identified by the cultivation-dependent methods such as fungi of the genera Penicillium and Cladosporium, but also providing a great contribution in the identification of several genera and species, not previously identified in these artworks, giving also a detailed overview of contaminants which
\end{abstract}

T. Rosado $\cdot$ J. Mirão $\cdot$ A. Candeias $\cdot$ A. T. Caldeira HERCULES Laboratory, Évora University, Largo Marquês de Marialva 8, 7000-809 Évora, Portugal

T. Rosado $\cdot$ A. Candeias $\cdot$ A. T. Caldeira

Évora Chemistry Centre and Chemistry Department, Évora

University, Rua Romão Ramalho 59, 7000-671 Évora, Portugal

J. Mirão

Évora Geophysics Centre and Geosciences Department, Évora

University, Rua Romão Ramalho 59, 7000-671 Évora, Portugal

\section{A. T. Caldeira $(\bowtie)$}

Évora Chemistry Centre and Chemistry Department, Colégio Luís António Verney, Rua Romão Ramalho no. 59, 7000-671 Évora, Portugal

e-mail: atc@uevora.pt was not possible with the other approaches. The results obtained on several mural painting samples show a strong relationship between the most deteriorated areas of the paintings and higher microbial contamination.

Keywords Biodegradation · Microbial diversity · Culture-dependent methods $\cdot$ DGGE $\cdot$ Pyrosequencing

\section{Introduction}

Microorganisms like bacteria, fungi, algae and lichens can play an important role in the biodegradation of cultural heritage, together with ageing, the chemical structure of the substrate and the environmental conditions such as humidity, temperature, $\mathrm{pH}$ and light $[1,2]$. Development of microorganisms on mural paintings may cause aesthetic and/or structural damage such as pigment discoloration, stains and biofilm formation on the painted surface, cracking and disintegration of paint layers and degradation of binders resulting in detachment of the paint layer [3-5].

Although the involvement of microorganisms in the degradation process is well acknowledged, the specific role of the different groups and species that compose the microbial communities is not yet well understood because methodologies tend to identify only easily cultivable and omit slow growing and uncultivable microorganisms. Identification of the microbial diversity present in cultural heritage is a crucial step to develop and apply correct conservation and mitigation methodologies and to prevent further contaminations [6].

The traditional way to identify the microbial diversity is based on the cultivation of microorganisms in specific nutrient media, but this approach detects less than $1 \%$ of the microbial communities present in the Earth [7]. To understand the phenomena that promotes the degradation of mural paintings, it is important to know as much as possible about the microbial 